\title{
Cloroquina: mecanismos de ação, efeitos colaterais e revisão de estudos sobre seu uso contra o SARS-CoV-2
}

\author{
Submetido - 29 jul. 2020 \\ Aprovado - 06 nov. 2020 \\ Publicado - 18 nov. 2020
}

\section{http://dx.doi.org/10.17648/sas.v2i1.47}

\begin{abstract}
Diogo Martins Ribeiro (D)
Licenciado em Educação Física - Faculdade de Educação e Meio Ambiente - FAEMA; e-mail: diogoadmr@gmail.com.
\end{abstract}

André Tomaz Terra Júnior (iD)

Doutor em Medicina (Clínica Cirúrgica) pela Faculdade de Medicina de Ribeirão Preto/Universidade de São Paulo (USP). Coordenador do Curso de Farmácia da FANORTE (Instituição de Ensino Superior de Cacoal -RO).; e-mail: andretomaz@usp.br.

Edson Rodrigues Cavalcante (D)

Graduado em Biblioteconomia pela Escola de Comunicação e Artes da Universidade de São Paulo (ECA/USP) e Pós em Docência do Ensino Superior, na Universidade Castelo Branco (UCB), e-mail: eds_caval@yahoo.com.br.

\section{RESUMO}

A Cloroquina é uma 4-aminoquinolina da classe dos agregados anfifílicos cationicos que tem chamado a atenção da comunidade científica devido aos seus efeitos antivirais. Inicialmente utilizada contra a malária, essa droga e principalmente sua derivada, Hidroxicloroquina, passaram a ser aplicadas na prática reumatológica e contra o Lúpus Eritematoso Sistêmico. Apesar de seu efeito contra diferentes doenças virais, ainda não é sabido se a Cloroquina é efetiva contra o COVID-19, doença causada pelo Severe Acute Respiratory Syndrome Coronavirus 2 (SARS-CoV2). Objetivando entender sobre o potencial da Cloroquina contra o novo coronavírus, uma busca de estudos originais foi feita na base de dados PubMed e especificamente em Oxford Academic Journals, The New England Journal of Medicine, Springer Nature, Nature Research e JAMA. Estudos in vitro parecem ser concordantes quanto aos benefícios da Cloroquina e sua derivada, Hidroxicloroquina, contra o SARS-CoV2. Estudos in vivo, no entanto, demonstram resultados controversos de ambas as drogas em relação ao tratamento ou profilaxia do COVID-19, sugerindo a necessidade de mais estudos.

Palavras-chave: Hidroxicloroquina; COVID-19; Doença respiratória aguda; Pandemia.

\section{Chloroquine: mechanisms of action, side effects and review of studies on its use against SARS-CoV-2}

\section{ABSTRACT}

Chloroquine is a 4-aminoquinoline of the class of cationic amphiphilic aggregates that has drawn the attention of the scientific community due to its antiviral effect. Initially used against malaria, this drug and mainly its derivative, Hydroxychloroquine, started to be applied in rheumatological practice and against Systemic Lupus Erythematosus. Despite its effect against different viral diseases, it is not yet known whether Chloroquine is effective against COVID-19, a disease caused by the Severe Acute Respiratory Syndrome Coronavirus 2 (SARS-CoV-2). In order to understand the potential of chloroquine against the new coronavirus, a search for original studies was made in the PubMed database and specifically in Oxford Academic Journals, The New England Journal of Medicine, Springer Nature, Nature Research and JAMA. 
In vitro studies seem to agree with the benefits of Chloroquine and its derivative, Hydroxychloroquine, against SARS-CoV-2. In vivo studies, however, demonstrate controversial results from both of these drugs regarding the treatment or prophylaxis of COVID-19, suggesting the need for further studies.

Keywords: Hydroxychloroquine; COVID-19; Acute respiratory disease; Pandemic.

\section{Cloroquina: mecanismos de acción, efectos secundarios y revisión de estudios sobre su uso contra el SARS-CoV-2}

\section{RESUMEN}

La cloroquina es una 4-aminoquinolina de la clase de agregados anfifílicos catiónicos que ha atraído la atención de la comunidad científica debido a sus efectos antivirales. Inicialmente utilizado contra la malaria, este medicamento y principalmente su derivado, la hidroxicloroquina, comenzó a aplicarse en la práctica reumatológica y contra el lupus eritematoso sistémico. A pesar de su efecto contra diferentes enfermedades virales, aún no se sabe si la cloroquina es efectiva contra COVID-19, una enfermedad causada por el Severe Acute Respiratory Syndrome Coronavirus 2 (SARS-CoV-2). Para comprender el potencial de la cloroquina contra el nuevo coronavirus, se realizaron búsquedas de estudios originales en la base de datos PubMed y específicamente en Oxford Academic Journals, The New England Journal of Medicine, Springer Nature, Nature Research y JAMA. Los estudios in vitro parecen estar de acuerdo con los beneficios de la cloroquina y su derivado, la hidroxicloroquina, contra el SARS-CoV-2. Sin embargo, los estudios in vivo demuestran resultados controvertidos de ambos fármacos en relación con el tratamiento o la profilaxis de COVID-19, lo que sugiere la necesidad de más estudios.

Palabras clave: Hidroxicloroquina; COVID-19; Enfermedad respiratoria aguda; Pandemia.

\section{Introdução}

Estudos recentes têm citado a Cloroquina como potencial droga a ser usada no tratamento de pacientes infectados pelo vírus SARS-CoV-2 (COLSON; ROLAIN; RAOULT, 2020; GAO; TIAN; YANG, 2020). Conhecida desde 1934 (SAVARINO et al., 2003), a Cloroquina é uma 4-aminoquinolina da classe dos agregados anfifílicos catiônicos (SIDHU; VERDIER-PINARD; FIDOCK, 2002; HALLIWELL 1997). Há um decréscimo na sua prescrição para o tratamento da malária devido à resistência por parte do protozoário Plasmodium (SAVARINO et al., 2003).

A Cloroquina e sua derivada, Hidroxicloroquina, são administradas oralmente e possuem ações farmacocinéticas parecidas (TONNESMANN; KANDOLF; LEWALTER, 2013), além de ambas poderem se acumular em tecidos contendo melanina, como nos olhos e pele, órgãos parenquimatosos, coração e no tecido musculoesquelético (TONNESMANN; KANDOLF; LEWALTER, 2013; DUCHARME; FARINOTTI, 1996). 
Ambas as drogas têm sido adotadas contra doenças antirreumáticas (SMOLEN et al., 2014). A Hidroxicloroquina, porém, tem uma maior indicação no tratamento de doenças como o Lúpus Eritematoso Sistêmico (FANOURIAKIS et al., 2019), Síndrome do Anticorpo Antifosfolipídeo (TEKTONIDOU et al., 2019) e a Síndrome de Sjögren (VIVINO et al., 2016), devido menor toxicidade (TONNESMANN; KANDOLF; LEWALTER, 2013).

Após o surto de casos de pneumonia inicialmente registrados em Wuhan, China (WU et al., 2020), o estudo da Cloroquina como possível meio contra o SARS-CoV-2 foi impulsionado devido a droga já ter demonstrado potencial contra diferentes vírus, como o HIV-1, Poliovírus, vírus da raiva (SAVARINO et al., 2001; KRONENBERGER; VRIJSEN; BOEYÉ, 1991; TSIANG; SUPERTI, 1984), Hepatites A e C (BISHOP, 1998; MIZUl et al., 2010), Ebola e membros da família coronavírus (DOWALL et al., 2015; BISHOP, 2015; SAVARINO et al., 2003; DE WILDE et al., 2014; VINCENT et al., 2005; KEYAERTS et al., 2004). No entanto, pode demonstrar efeitos controversos, como mostram estudos em relação aos vírus da Influenza (PATON et al., 2011; WU et al., 2015), Chikungunya (ROQUES et al., 2018), Dengue (TRICOU et al., 2010; BORGES; CASTRO; FONSECA, 2013) e o vírus Hendra (MAHALINGAM et al., 2012).

O baixo custo da Cloroquina, além de sua ampla disponibilidade e histórico de segurança em relação ao seu uso são outros possíveis motivos que impulsionaram o interesse para estudo dessa droga contra o COVID-19 (LIU et al., 2020).

Conforme mencionam Colson, Rolain e Raoult (2020), referente ao uso de drogas já existentes contra novas doenças, "[...] é importante ser capaz de usar drogas as quais foram evidenciadas como inócuas e cuja farmacocinética e dosagem ideal são bem conhecidas.".

Este trabalho foi elaborado objetivando a reunião de informações sobre a Cloroquina, referente aos mecanismos de ação elucidado em outras patologias e possíveis relações para eficácia contra o vírus SARS-CoV-2, buscando-se entender o potencial dessa droga contra o COVID-19. 


\section{Metodologia}

Realizou-se uma busca de estudos na literatura científica, tanto originais quanto revisões, sobre os mecanismos de ação e efeitos colaterais da Cloroquina/Hidroxicloroquina. As buscas concentraram-se sobre fontes científicas que adotam a revisão por pares para publicação, com faixa temporal iniciada na década de 40 , quando os primeiros estudos sobre a Cloroquina foram publicados - conforme o mecanismo de busca do PubMed - e se estende até julho de 2020.

Em segunda parte foram buscados, no PubMed, estudos originais revisados por pares. Para inclusão, não foram visados delineamentos metodológicos específicos, porém os artigos deveriam avaliar a Cloroquina ou Hidroxicloroquina in vivo ou in vitro. A faixa temporal adotada é de 01/01/2020 até $24 / 07 / 2020$. Os estudos foram buscados de acordo com os passos apresentados no Quadro 1.

Quadro 1. Metodologia para busca de estudos originais.

\begin{tabular}{|l|l|}
\hline \multicolumn{3}{|c|}{ Estudos originais - PubMed } \\
\hline Combinação: & $\begin{array}{l}(\text { Chloroquine) AND (SARS-CoV-2)) OR } \\
\text { (COVID-19) }\end{array}$ \\
\hline \multirow{3}{*}{ Filtros aplicados: } & $\begin{array}{l}\text { Full text; Clinical Trial; Clinical Study; } \\
\text { Clinical Trial, Phase I; Clinical Trial, Phase } \\
\\
\text { II; Randomized control trial; Observational } \\
\text { study; Controlled clinical trial; Comparative } \\
\text { study }\end{array}$ \\
\hline
\end{tabular}

Para incrementar a discussão sobre o potencial da Cloroquina contra - SARS-CoV-2, busca externa foi realizada especificamente em Oxford Academic Journals, The New England Journal of Medicine, Nature Research, JAMA e Springer Nature, objetivando encontrar estudos originais não indicados pelo PubMed. Estudos citados por outros autores também foram considerados. 


\section{Resultados e discussão}

O total de 77 estudos foram selecionados para compor discussão sobre os mecanismos de ação e efeitos colaterais da Cloroquina. Já, conforme a metodologia indicada para busca de estudos originais, um total de 31 itens foram encontrados, tendo 13 sido incluídos, conforme mostrado na Figura 1.

Número de itens

encontrados em

pesquisa sobre

estudos originais $(n=$ 31)
Número de itens

após eliminar os

duplicados $(n=30)$
Número de itens

remanescentes,

após exclusão

justificada $(n=13)$

Figura 1. Estudos originais encontrados no PubMed.

Os estudo originais são destacados no Quadro 2, sendo indicados a fonte, autoria, elementos abordados e design do estudo. Em síntese, 11 estudos envolveram a Hidroxicloroquina, enquanto apenas 3 envolveram a Cloroquina.

Quadro 2. Características dos estudos originais encontrados no PubMed.

\begin{tabular}{|c|l|l|}
\hline Autor(es) & $\begin{array}{l}\text { Elemento(s) } \\
\text { abordado(s) }\end{array}$ & $\begin{array}{l}\text { Design do } \\
\text { estudo }\end{array}$ \\
\hline Borba et al. & $\begin{array}{l}\text { Difosfato } \\
\text { Cloroquina }\end{array}$ & $\begin{array}{l}\text { Ensaio } \\
\text { paralelo, } \\
\text { duplo-cego, } \\
\text { randomizado, } \\
\text { em fase llb }\end{array}$ \\
\hline Gautret et al. & $\begin{array}{l}\text { Hidroxicloroquina, } \\
\text { Azitromicina }\end{array}$ & $\begin{array}{l}\text { Estudo } \\
\text { observacional } \\
\text { piloto }\end{array}$ \\
\hline Geleris et al. & Hidroxicloroquina & $\begin{array}{l}\text { Estudo } \\
\text { observacional }\end{array}$ \\
\hline Goicoechea & $\begin{array}{l}\text { Hidroxicloroquina, } \\
\text { Lopinavir/Ritonavir, } \\
\text { Azitromicina, } \\
\text { ct al. }\end{array}$ & $\begin{array}{l}\text { Estudo } \\
\text { retrospectivo, } \\
\text { tocilizumabe }\end{array}$ \\
\hline
\end{tabular}




\begin{tabular}{|c|c|c|}
\hline Huang et al. & Cloroquina & Estudo clínico \\
\hline $\begin{array}{l}\text { Lecronier et } \\
\text { al. }\end{array}$ & $\begin{array}{l}\text { Hidroxicloroquina, } \\
\text { Lopinavir/Ritonavir }\end{array}$ & $\begin{array}{l}\text { Análise } \\
\text { retrospectiva } \\
\text { observacional }\end{array}$ \\
\hline $\begin{array}{l}\text { Mahévas et } \\
\text { al. }\end{array}$ & Hidroxicloroquina & $\begin{array}{l}\text { Estudo } \\
\text { comparativo } \\
\text { observacional }\end{array}$ \\
\hline Molina et al. & $\begin{array}{l}\text { Hidroxicloroquina, } \\
\text { Azitrocimina }\end{array}$ & $\begin{array}{l}\text { Estudo } \\
\text { prospectivo }\end{array}$ \\
\hline Saleh et al. & $\begin{array}{l}\text { Cloroquina, } \\
\text { Hidroxicloroquina, } \\
\text { Azitromicina }\end{array}$ & $\begin{array}{l}\text { Estudo } \\
\text { prospectivo } \\
\text { observacional }\end{array}$ \\
\hline Tang et al. & Hidroxicloroquina & $\begin{array}{l}\text { Ensaio } \\
\text { controlado } \\
\text { randomizado, } \\
\text { aberto }\end{array}$ \\
\hline $\begin{array}{l}\text { Vastarella et } \\
\text { al. }\end{array}$ & Hidroxicloroquina & $\begin{array}{l}\text { Estudo } \\
\text { retrospectivo } \\
\text { observacional }\end{array}$ \\
\hline Dastan et al. & Hidroxicloroquina & $\begin{array}{l}\text { Estudo } \\
\text { prospectivo } \\
\text { não controlado }\end{array}$ \\
\hline $\begin{array}{l}\text { Fernández- } \\
\text { Ruiz et al. }\end{array}$ & $\begin{array}{l}\text { Hidroxicloroquina, } \\
\text { Lopinavir/Ritonavir }\end{array}$ & $\begin{array}{l}\text { Série de casos } \\
\text { em único } \\
\text { centro }\end{array}$ \\
\hline
\end{tabular}

Conforme quadro 3, de acordo com pesquisa externa feita especificamente em Oxford Academic Journals, The New England Journal of Medicine, Nature Research, JAMA e Springer Nature, 11 estudos foram adicionados. A partir de citação de outros autores, 1 estudo foi adicionado, enquanto 1 estudo foi encontrado acidentalmente. Ressalta-se que documento de Gao, Tian e Yang não é um estudo científico, mas sim um pronunciamento público referente à Cloroquina, o qual foi usado neste artigo por seu alto índice de citações. Em síntese, 10 estudos abordaram a Hidroxicloroquina, enquanto 3 envolveram tanto a Cloroquina como a Hidroxicloroquina e 3 envolveram apenas a Cloroquina. 
Quadro 3. Resultados de acordo com busca externa.

\begin{tabular}{|c|c|c|c|}
\hline Fonte & Autor(es) & $\begin{array}{l}\text { Elemento(s) } \\
\text { abordado(s) }\end{array}$ & Design do estudo \\
\hline $\begin{array}{l}\text { The New England } \\
\text { Journal of Medicine }\end{array}$ & Cavalcanti et al. & $\begin{array}{l}\text { Hidroxicloroquina, } \\
\text { Azitromicina }\end{array}$ & $\begin{array}{c}\text { Ensaio randomizado, } \\
\text { controlado, aberto, } \\
\text { multicentro }\end{array}$ \\
\hline $\begin{array}{l}\text { The New England } \\
\text { Journal of Medicine }\end{array}$ & Boulware et al. & Hidroxicloroquina & $\begin{array}{l}\text { Ensaio randomizado, } \\
\text { placebo-controlado, } \\
\text { duplo-cego }\end{array}$ \\
\hline JAMA & Mercuro et al. & $\begin{array}{l}\text { Hidroxicloroquina, } \\
\text { Azitromicina }\end{array}$ & Estudo de Coorte \\
\hline JAMA & Rosenberg et al. & $\begin{array}{l}\text { Hidroxicloroquina, } \\
\text { Azitromicina }\end{array}$ & $\begin{array}{c}\text { Estudo retrospectivo } \\
\text { de Coorte }\end{array}$ \\
\hline JAMA & Bessière et al. & $\begin{array}{l}\text { Hidroxicloroquina, } \\
\text { Azitromicina }\end{array}$ & Série de casos \\
\hline Springer Nature & $\begin{array}{c}\text { Van de Broek et } \\
\text { al. }\end{array}$ & Cloroquina & $\begin{array}{c}\text { Estudo retrospectivo, } \\
\text { observacional de } \\
\text { coorte }\end{array}$ \\
\hline Springer Nature & Hsia et al. & $\begin{array}{l}\text { Cloroquina, } \\
\text { Hidroxicloroquina, } \\
\text { Azitromicina } \\
\end{array}$ & Estudo observacional \\
\hline Springer Nature & Sinkeler et al. & Cloroquina & $\begin{array}{c}\text { Estudo retrospectivo, } \\
\text { observacional de } \\
\text { coorte }\end{array}$ \\
\hline $\begin{array}{c}\text { Encontrado } \\
\text { acidentalmente }\end{array}$ & Magagnoli et al. & Hidroxicloroquina & Estudo retrospective \\
\hline $\begin{array}{l}\text { Oxford Academic } \\
\text { Journals }\end{array}$ & Yao et al. & $\begin{array}{c}\text { Cloroquina, } \\
\text { Hidroxicloroquina }\end{array}$ & In vitro \\
\hline Nature Research & Liu et al. & $\begin{array}{l}\text { Hidroxicloroquina, } \\
\text { Cloroquina }\end{array}$ & In vitro \\
\hline Nature Research & Wang et al. & $\begin{array}{c}\text { Remdesivir, } \\
\text { Hidroxicloroquina }\end{array}$ & In vitro \\
\hline $\begin{array}{c}\text { Citação de Gautret } \\
\text { et al. }\end{array}$ & $\begin{array}{l}\text { Gao, Tian e } \\
\text { Yang }\end{array}$ & $\begin{array}{l}\text { Fosfato de } \\
\text { Cloroquina }\end{array}$ & $\begin{array}{l}\text { Pronunciamento } \\
\text { público }\end{array}$ \\
\hline
\end{tabular}

Estudo de Furst et al. (1999) sugere que o uso de $1200 \mathrm{mg} / \mathrm{d}^{1}$ (equivalente a $750 \mathrm{mg} / \mathrm{d}$ de Cloroquina) de Hidroxicloroquina em 6 semanas é tolerável. Enfatiza-se, no entanto, a administração de dose diária inferior a $25 \mathrm{mg} / \mathrm{kg}$, podendo gerar fatalidade quando a droga é aplicada a $30 \mathrm{mg} / \mathrm{kg}$ (BRASIL, 2020). Além disso, segundo Devaux et al. (2020), a "[...] Hidroxicloroquina pode ser usada com boa tolerância em altas doses por

\footnotetext{
${ }^{1} \mathrm{Mg} / \mathrm{d}=$ Miligramas por dia.
} 
longos períodos.", o que sugere a possibilidade do uso desta última para o alcance de maior efeito antiviral.

Diferentes revisões apontam a Cloroquina ou Hidroxicloroquina como possíveis agentes contra o vírus SARS-CoV-2 (DEVAUX et al., 2020; DONG; HU; GAO, 2020; LAI et al., 2020; TOURET; LAMBALLERIE, 2020; ZHANG et al., 2020; ZHOU et al., 2020; CORTEGIANI et al., 2020). Porém, conforme Guastalegname e Vallone (2020) alertam, apesar de ser apresentada a eficácia in vitro de ambas as drogas, deve-se ter cautela no uso clínico delas, pois ainda falta clareza em relação à patogênese do COVID-19, bem como há a necessidade de esperar por ensaios clínicos, para se obter resultados sobre os efeitos das duas drogas no organismo humano.

Touret e Lamballerie (2020) enfatizam que os ensaios clínicos devem ser publicados após revisão por pares, expondo detalhes, pois assim a comunidade científica pode analisar os resultados e corroborar eficácia a partir de estudos prospectivos.

\section{Mecanismos de ação da cloroquina/hidroxicloroquina}

\section{Mecanismos antimaláricos}

Em resumo, ações de antimaláricos, incluindo-se a Cloroquina e a Hidroxicloroquina, são apresentados na Tabela 1.

\section{Tabela 1. Mecanismos associados a drogas antimaláricas.}

Bloqueio do processamento do antígeno a partir do aumento do $\mathrm{pH}$ endossômico

Diminuição na produção de citocinas mediada por macrófagos

Inibição da fosfolipase A2 e C

Estabilização de membranas lisossomais

Levam à ação antioxidante e bloqueia a liberação de superóxido*

Absorção de luz ultravioleta

Diminuição na produção de estrogênio

Auxilia na hipoglicemia 
Bloqueia a doença do enxerto contra hospedeiro*

Inibe a agregação e adesão plaquetária

Induz à apoptose*

Ações parecidas com a quinidina

Efeitos antimicrobianos

Efeitos antiproliferativos*

Dissolução de complexos imunes circulantes*

Retirado e adaptado de Wallace (2001).

Os mecanismos destacados com asterisco são alcançados a partir da administração das drogas em níveis superiores aos aplicados na prática clínica reumatológica (WALLACE, 2001), >4mg/kg ao dia por 1 a 6 meses, conforme Brasil (2020). Além dos mecanismos citados na Tabela 1, também são associados a drogas antimaláricas os efeitos antitrombótico, hipolipemiante e no metabolismo ósseo (RODRIGUEZ-CARUNCHO; MARSOL, 2014).

Diferentes mecanismos antimaláricos específicos são associados à Cloroquina, como a inibição de hemozoína (CORONADO; NADOVICH; SPADAFORA, 2014), processo essencial para a disponibilização de espaço e crescimento do Plasmodium nas Hemácias (EGAN, 2008). A droga ainda pode gerar aumento de radicais livres no vacúolo digestivo do parasita a partir da liberação da chamada "fração heme" (COMBRINCK et al., 2013). Em síntese, a Cloroquina impede a desintoxicação do parasita a partir da inibição de transformação da heme em hemozoína, provocando acúmulo da heme e consequente morte do parasita ( $\mathrm{CHOU}$; FITCH, 1992).

Kwiek, Haystead e Rudolph (2004) apontam o efeito inibitório da Cloroquina sobre a Quinona Redutase 2, responsável por catalisar a desintoxicação metabólica das quinonas (CHEN; WU; KNOX, 2000; DINKOVA-KOSTOVA; TALALAY, 2000; LONG; JAISWAL, 2000), assim provocando estresse oxidativo e reduzindo a ação do parasita $(B O Z D E C H$; GINSBURG, 2004). 
Ações da Cloroquina no DNA do parasita também são discutidos por Stephen e Stuart (2000), sendo indicadas alterações estruturais e sequente impedimento da síntese. Outros mecanismos da Cloroquina são propostos conforme estudos citados em revisão de Tewari et al. (2017), como a ação de intercalação da Cloroquina no DNA do parasita em concentrações fisiológicas (MESHNICK, 1983), alteração no pH do vacúolo digestivo e inibição de heme polimerase (YAYON, 1983), e formação de complexo Cloroquina-Ferriprotoporfirina IX (SUGIOKA, 1987). Contudo, ainda não há conhecimento sobre os mecanismos exatos da Cloroquina que provocam a morte do parasita (TEWARI et al., 2017).

\section{Mecanismos anticâncer}

Conforme Al-Bari (2015), as abordagens mais comuns dos análogos da Cloroquina no que se refere ao tratamento contra cânceres são a inibição da autofagia e sensibilização das células malignas à radiação e aos agentes quimioterápicos. Além da inibição autofágica, Plantone e Koudriavtseva (2018) citam as ações antiproliferativas e antimutagênicas da Cloroquina e Hidroxicloroquina.

Rubinsztein, Codogno e Levine (2012) mencionam que "a autofagia é uma via de degradação lisossômica essencial e conservada que controla a qualidade do citoplasma, eliminando agregados de proteínas e organelas danificadas.".

De acordo com Maes et al. (2016), a partir da alcalinização dos compartimentos ácidos, estes os quais a Cloroquina se encontra presa à protonação, ocorre o comprometimento de eventos de fusão e a interrupção da degradação da carga endossômica e autofágica, gerando bloqueio do fluxo autofágico basal e estimulado.

Avniel-Polak et al. (2016) indicam que a cloroquina inibe a fusão entre os autofagossomos e lisossomos, provocando boqueio da etapa de degradação lisossomal, assim induzindo ao acúmulo de corpos autofágicos. 
Ademais, sugere-se que a inibição autofágica e ativação de apoptose, promovidas pela Cloroquina, podem provocar maior sensibilização, potencializando os efeitos da radioterapia e de agentes quimioterápicos (SOLOMON; LEE, 2009).

Em resumo, a autofagia induzida pela Cloroquina parece ser de importância como elemento auxiliar no tratamento de vários tipos de câncer, como o câncer de mama, de bexiga e endometrial (CAVE et al., 2018; WANG et al., 2018; FUKUDA et al., 2015), colorretal, mieloma múltiplo e linfoma primário de efusão (ZHU et al., 2019; SCHONEWOLF et al., 2014; JARAUTA et al., 2016; ALAM et al., 2016), carcinoma na nasofaringe, pancreático (AGA et al., 2019; WANG et al., 2019) e outros tipos (AL-BARI, 2015).

\section{Mecanismos anti-inflamatórios e imunomodulatórios}

Al-Bari (2015) cita, em estudo de revisão, 16 mecanismos antiinflamatórios e imunomodulatórios associados a análogos da Cloroquina, dentre os quais 11 são fundamentados por estudos específicos relacionados à Cloroquina e Hidroxicloroquina, adicionados pelo autor deste artigo, conforme Tabela 2.

Tabela 2. Mecanismos anti-inflamatórios e imunomodulatórios associados à Cloroquina/Hidroxicloroquina.

Inibição no processo de apresentação e processamento de antígeno (FOX e KANG, 1993; PETRI, 1998).

Inibição na estimulação de células TLR9, participativas em resposta imunológicas (SCHREZENMEIER; DORNER, 2020).

Inibição na produção de citocinas e liberação por células T: IL1, 2, 6 ou 18; TNFa (PICOT et a.,1991).

Inibição da atividade citotóxica de linfócitos $T$ e linfócitos CD4+ autorreativos (RODRIGUEZ-CARUNCHO; MARSOL, 2014; FOX, 1993).

Redução nos níveis de quimiocina CCL2 e CXCL10 em Lúpus eritematoso sistêmico (DOMINGUEZ-GUTIERREZ et al., 2014).

Inibição de Fosfolipase A2 e antagonismo aos efeitos de


protaglandinas e leucotrienos (BONDESON; SUNDLER, 1998;

LOFFLER et al., 1985; VAN BEEK; PIETTE, 2001).

Ação de bloqueio ou filtro contra luz ultravioleta (LESTER et al., 1967).

Inibição de sinalização de cálcio nos receptores de células $T$ e $B$ (GOLDMAN et al., 2000.

Inibição de metaloproteinase matriz (LESIAK et al., 2010).

Inibição da expressão de micro-RNA (CHAFIN et al., 2013).

Diminuição nas citocinas relacionadas à TH17 (SILVA et al., 2013).

Retirado e adaptado de Al-Bari (2015).

São outros mecanismos: ligação com o DNA e inibição competitiva de anticorpos anti-DNA; aumento na atividade de linfócitos $\mathrm{T}$ regulatórios e níveis regulados de TNFa, IL2 e IL-10; DNA e RNA diminuídos e síntese proteica em timócitos; bloqueio das ações da histamina endógena e exógena e inibição da formação de óxido nítrico por macrófagos e produção induzida de espécies reativas de oxigênio em células astrogliais (AL-BARI, 2015).

\section{Possíveis mecanismos de ação da cloroquina contra o SARS-CoV-2}

Em relação ao Severe Acute Respiratory Syndrome Coronavirus (SARS-CoV), a Cloroquina demonstra-se efetiva in vitro contra a replicação do vírus em células Vero E6 (VINCENT et al., 2005; KEYAERTS et a., 2004). Conforme Savarino et al. (2003), a Cloroquina age sobre o pH endossômico, prejudicando a fusão do vírus com a célula hospedeira, bem como interfere na glicosilação dos receptores celulares do SARS-CoV.

Além do mais, há a hipótese que a droga possa inibir a biossíntese de ácido siálico, o qual é presente na enzima conversora de angiotensina 2 (ACE2, sigla em inglês), assim prejudicando a ligação do SARS-CoV com a célula hospedeira (SAVARINO et al., 2006). A ACE2 é evidenciada como responsável por receber a espícula tanto do SARS-CoV como do SARSCoV-2 (LI et al., 2003; WALLS et al., 2020).

Em consonância, Fantini et al. (2020) apontam que a ligação da Cloroquina ou a Hidroxicloroquina com ácidos siálicos e gangliosídios pode 
inibir a interação do SARS-CoV-2 com a célula hospedeira. Ademais, a inibição do Glicogênio Sintase Quinase $3 \beta$ (GSK3 $\beta$ ) é sugerida como possível mecanismo de ação da Cloroquina contra o SARS-CoV-2 (EMBI; GANESAN; SIDEK, 2020), assim podendo servir como norte para estudo de intervenções clínicas específicas.

$\mathrm{Hu}$, Frieman e Wolfamn (2020) também sugerem que um dos possíveis mecanismos da Cloroquina contra o SARS-CoV-2 é a diminuição na habilidade de células de realizarem endocitose mediada por clatrina em nanoestruturas, devido à supressão da proteína de montagem da clatrina de ligação ao fosfatidilinositol ${ }^{2}$ (PICALM, sigla em inglês).

\section{Efeitos colaterais da cloroquina/hidroxicloroquina}

Segundo Al-Bari et al. (2015), as condições adversas mais comuns causadas pela Cloroquina são a retinopatia, cardiomiopatia, neuromiopatia e miopatia. Ademais, há contraindicações absolutas e relativas quanto ao uso de antimaláricos, demonstradas no Quadro 4.

Quadro 4. Contraindicações quanto ao uso de antimaláricos.

\begin{tabular}{|c|c|}
\hline Contraindicações absolutas & Contraindicações relativas \\
\hline $\begin{array}{l}\text { - Histórico de retinopatia; } \\
\text { - Hipersensibilidade } \\
\text { imunológica; } \\
\text { - Terapia supressiva de } \\
\text { medula óssea. }\end{array}$ & $\begin{array}{l}\text { - Insuficiência renal; } \\
\text { - Doença hepática; } \\
\text { - Doença hematológica; } \\
\text { - Deficiência de glicose-6- } \\
\text { fosfato desidrogenase } \\
\text { (G6PD); } \\
\text { - Doença neuromuscular; } \\
\text { - Doença psiquiátrica; } \\
\text { - Psoriasis }{ }^{3} \text {. }\end{array}$ \\
\hline
\end{tabular}

Retirado e adaptado de Rodrigues-Caruncho e Marsol (2014).

2 Tradução literal de "Phosphatidylinositol binding clathrin assembly protein".

${ }^{3}$ Conforme apresentado na tabela original, os autores adicionaram interrogação: "Psoriasis?". 


\section{Retinopatia}

A ocorrência de retinopatia é dependente da proporção da dose diária e tempo de uso da Cloroquina, e os efeitos agudos desta droga no metabolismo de células retinianas podem ser causados por altas doses experimentais, mas ainda não há clareza em relação aos processos que levam ao estado clínico de toxicidade (MARMOR et al., 2016).

Conforme Mahon et al. (2004), a interrupção da função lisossômica intracelular nas células epiteliais do pigmento da retina (RPE, sigla em inglês) e nos neurônios da retina pode ser causa provável da retinopatia por Cloroquina. Sisternes et al. (2015) avaliaram a toxicidade da Hidroxicloroquina na retina e registraram danos nos fotorreceptores, bem como sugerem que a progressão da toxicidade leva a danos descritos como possível maculopatia difusa. A progressão da retinopatia envolvendo o RPE é destacada mesmo após a cessação do uso da Hidroxicloroquina, causando a perda de espessura da fóvea e estrutura do cone, e é associada com a magnitude da patologia e a detecção da toxicidade em estágios iniciais (MARMOR; HU, 2014).

Além do mais, ainda quanto ao uso da Hidroxicloroquina, são fatores que podem aumentar os riscos associados à retinopatia: dose $>6,5$ $\mathrm{mg} / \mathrm{kg} /$ dia ou dose cumulativa $>1000 \mathrm{~g}$; período de tratamento por $>5$ anos; disfunção renal ou hepática; retinopatia pré-existente; e idade mais avançada (DING et al., 2016). Apesar de a Hidroxicloroquina ser citada como causadora de retinopatia, esta parece estar mais comumente associada à Cloroquina, possivelmente em razão da maior toxicidade desta última (SCHREZENMEIER; DORNER, 2020).

\section{Cardiomiopatia}

A Hidroxicloroquina é considerada menos tóxica que a Cloroquina (LIU et al., 2020; DEVAUX et al., 2020), no entanto, é sugerido que ambas podem levar a condições adversas, incluindo complicações cardíacas (CHATRE et al., 2018). Toxicidade cardíaca relacionada à Cloroquina e Hidroxicloroquina parece ser uma complicação rara, porém, quando há 
manifestações cardíacas devido ao tratamento em relação a ambas as drogas, os danos podem ser irreversíveis (CHATRE et al., 2018).

Diferentes estudos sugerem cautela na administração da Hidroxicloroquina, uma vez que pode estar associada com potenciais adversidades, incluindo o prolongamento do intervalo QT (MERCURO et al., 2020; PATEL et al., 2020; YAZDANY; KIM, 2020; BESSIÈRE et al., 2020; SAPP et al., 2020). Conforme revisão de Schrezenmeier e Dorner (2020), no entanto, a Hidroxicloroquina pode oferecer proteção cardíaca em longo prazo a partir da diminuição dos níveis de glicose e Hiperlipidemia, bem como é utilizada como medicamento de suporte para a aspirina, contra possíveis complicações cardíacas relacionadas ao Lúpus eritematoso sistêmico.

A Tabela 4 apresenta abordagem geral sobre complicações cardíacas por citotoxicidade associada à Cloroquina e Hidroxicloroquina, conforme estudo sistemático de Chatre et al. (2018).

\section{Tabela 3. Complicações cardíacas associadas à Cloroquina e} Hidroxicloroquina.

Bloqueio atrioventricular

Bloqueio atrioventricular de primeiro ou segundo grau

Bloqueio atrioventricular completo

Bloqueio do ramo direito ou esquerdo

Desordens valvulares

Doença arterial coronariana

Infarto do miocárdio

Falhas ventriculares direitas

Hipertrofia da parede arterial pulmonar

Hipertrofia ventricular esquerda

Hipocinesia ventricular

Disfunção diastólica

Hipertrofia biventricular

Fração de ejeção $<40 \%$, entre 40 e $60 \%$ e $>60 \%$

Retirado e adaptado de Chatre et al. (2018). 


\section{Neuromiopatia e Miopatia}

A neuromiopatia e a miopatia são associadas a análogos da Cloroquina, sendo a primeira ocasionada por altas doses e a segunda por tempo de uso estimado de 5-7 meses. Ambas, diferentemente da cardiomiopatia, são reversíveis (AL-BARI, 2015).

Yogasundaram et al. (2014) citam a suspeita em relação à similaridade entre a causa metabólica por trás da cardiomiopatia e a neuromiopatia, uma vez que ambas possuem características histológicas semelhantes.

Em relação à miopatia, Neville et al. (1979), após avaliação por biópsia, descrevem distintas Citostomas com perfil curvilinear ${ }^{4}$ (CCPs, sigla em inglês) em uma paciente que, após a cessação de tratamento com Cloroquina, desenvolveu fraqueza muscular. É sugerido pelos autores que as CCPs podem ser resultado dos efeitos da droga nos sistemas membranares dentro das células musculares.

Eadie e Ferrier (1966) sugerem que a Cloroquina possa provocar a miopatia através de danos por inibição a enzimas relacionadas ao metabolismo de glicogênio. Ainda conforme os autores, o caso por eles avaliado, além de outros casos relacionados e citados, reportam características de unidades motoras associadas típicas de doença muscular primária.

Estudo em coelhos, dirigido por Smith e O'Grady (1966), mostrou que a ação necrótica nas fibras musculares cardíacas e esqueléticas podem estar associadas à miopatia induzida por Cloroquina, sendo a necrose proeminente no músculo cardíaco. O estudo também demonstra que os danos foram principalmente nas fibras vermelhas (tipo 1), possivelmente devido à ligação da Cloroquina por metemoglobina.

Autópsia realizada por Abdel-Hamid, Oddis e Lacomis (2008) em dois pacientes com suspeita de miopatia aponta as seguinte alterações

\footnotetext{
4 Tradução literal de "cytosomes with curvilinear profiles".
} 
patognomônicas gerais: variação anormal no tamanho das fibras (diâmetro 20-75 $\mu \mathrm{m}$ ) com fibras atróficas esparsas, cariopicnose e leve excesso de núcleos internalizados sem infiltrados inflamatórios.

\section{Outros efeitos colaterais}

Efeitos cutâneos, neuromusculares, gastrointestinais e hematológicos também são evidenciados como efeitos colaterais pelo uso da Cloroquina ou Hidroxicloroquina (RODRIGUEZ-CARUNCHO; MARSOL, 2014).

\section{Cloroquina/hidroxicloroquina e SARS-CoV-2}

Borba et al. (2020) avaliaram duas dosagens de difosfato de Cloroquina em 81 pacientes hospitalizados: baixa dosagem, idade média de 47.4 anos, referente a $450 \mathrm{mg}$ duas vezes no dia 1 e uma vez por outros 4 dias; alta dosagem, idade média de 54.7 anos, referente a $600 \mathrm{mg}$ duas vezes por 10 dias. Participação foi iniciada antes dos resultados laboratoriais. Posteriormente, 62 pacientes foram confirmados com COVID19 e os outros apresentavam compatibilidade epidemiológica e clínica com a doença. Azitromicina também foi administrada para todos os pacientes, conforme protocolo, bem como $89.6 \%$ dos pacientes receberam Oseltamivir, por suspeita de influenza.

A abordagem de alta dosagem (1200mg de Cloroquina por 10 dias) foi descontinuada em pacientes com doença severa, uma vez que os riscos se sobressaíram aos benefícios. Além do mais, não foi demonstrado benefício claro da Cloroquina sobre a taxa de letalidade. Também não foi indicada diminuição na carga viral em secreções respiratórias de pacientes tratados com Cloroquina, independentemente da dosagem administrada e mesmo com associação da Azitromicina.

Huang et al. (2020) avaliaram os efeitos da Cloroquina via oral (500mg duas vezes por dia durante 10 dias) e do Lopinavir/Ritonavir via oral (400/100mg duas vezes ao dia durante 10 dias) em dois grupos formados por 10 e 12 pessoas, respectivamente, sendo todos classificados com doença de moderada a severa. Foi demonstrada vantagem do tratamento 
com Cloroquina sobre o tratamento com Lopinavir/Ritonavir, levando a melhor recuperação geral e recuperação mais rápida da função pulmonar, além dos pacientes tratados com Cloroquina terem sido dispensados do hospital mais cedo.

Saleh et al. (2020) conduziram estudo observacional prospectivo que acompanhou 201 pacientes hospitalizados, idade média de 58.5 anos, tratados com Cloroquina (apenas 10 pacientes) ou Hidroxicloroquina (191 pacientes). 119 receberam a combinação Cloroquina ou Hidroxicloroquina e Azitromicina. As doses aplicadas foram 500mg de Cloroquina via oral duas vezes por 1 dia e 500mg/dia por outros 4 dias; 400mg de Hidroxicloroquina via oral duas vezes por 1 dia e $200 \mathrm{mg}$ duas vezes ao dia por outros 4 dias; $500 \mathrm{mg} /$ dia de Azitromicina via oral ou intravenosa por 5 dias. Aumento do intervalo QT foi indicado independentemente do tipo de tratamento, tendo sido maior na população que recebeu a combinação Cloroquina/Hidroxicloroquina e Azitromicina. Destaca-se, porém, que a descontinuação prematura devido prolongamento de intervalo QT ocorreu apenas para 7 pacientes.

Em estudo de Gautret et al. (2020), dois grupos foram divididos: 20 pacientes tratados com 600mg/dia de Hidroxicloroquina por 10 dias e 16 dentro do grupo controle, média de idade de 51.2 e 37.3 anos, respectivamente. Dentre aqueles no primeiro grupo, 6 receberam Azitromicina (500mg no dia 1 e $250 \mathrm{mg} /$ dia por outros quatro dias) juntamente com Hidroxicloroquina. A Hidroxicloroquina é indicada como passível de diminuir a carga viral nasofaríngea do SARS-CoV-2, podendo ser potencializada pela Azitromicina.

Molina et al. (2020) avaliaram o potencial da combinação Hidroxicloroquina e Azitromicina em 11 pacientes hospitalizados com idade média de 58.7 anos, tendo 8 deles algum fator de risco associado ao COVID-19. Foram aplicadas as mesmas dosagens utilizadas por Gautret et al. (111) durante 10 dias, porém não foi identificado benefício da combinação na recuperação dos pacientes. 
Geleris et al. (2020) realizaram estudo observacional de coorte que incluiu 1376 pacientes hospitalizados, acompanhados durante a média de 22.5 dias. 811 pacientes, em condição mais intensa da doença na linha de base, receberam 600mg de Hidroxicloroquina duas vezes no primeiro dia e $400 \mathrm{mg} /$ dia por uma média de 5 dias. Outros 565 não receberam Hidroxicloroquina. Durante o período de estudo, de 346 pacientes, 166 morreram sem receber intubação e 180 foram intubados. No total, 232 pacientes morreram, sendo 66 após intubação; e 119 permaneceram hospitalizados (24 não intubados) no período de finalização da coleta de dados. Não foi demonstrada associação entre o aumento ou diminuição do risco de intubação ou morte entre pacientes que receberam ou não o tratamento com Hidroxicloroquina.

Conforme estudo de Goicoechea et al. (2020), em referência a 36 pacientes tratados com hemodiálise e infectados pelo SARS-CoV-2, não há indicação de qualquer benefício ou malefício associado ao tratamento incluindo Hidroxicloroquina. Em detalhe, em primeira fase, durante nove dias, os pacientes eram tratados a partir da combinação Lopinavir/Ritonavir, Hidroxicloroquina e Interferon beta. Em segunda fase, durante vinte e um dias, o tratamento passou a ser com a administração de Lopinavir/Ritonavir e Hidroxicloroquina ou Azitromicina e Hidroxicloroquina. Corticosteróides e Tocilizumabe foram indicados para situações severas. De 36 pacientes, receberam Lopinavir/Ritonavir: 27; Hidroxicloroquina: 35; Azitromicina: 23; corticosteróides: 17; interferon beta: 13; e Tocilizumabe: 2.

Apresentada em tabela suplementar 1 por Goicoechea et al. (2020), a dosagem de Cloroquina administrada se refere a $400 \mathrm{mg} / 12 \mathrm{~h}$ no primeiro dia e $200 \mathrm{mg} / 12 \mathrm{~h}$ nos próximos $10-14$ dias. Os pacientes receberam $400 \mathrm{mg} / 100 \mathrm{mg}$ de Lopinavir/Ritonavir duas vezes ao dia por 10-14 dias. Interferon beta (250 $\left.\mu^{5} \mathrm{sc} / 48 \mathrm{~h}\right)$ foi descontinuado em segunda fase, enquanto a Azitromicina (500mg no dia 1, 250mg/dia por 4-5 dias) foi incluída. Na segunda fase, corticosteróides foram administrados na dosagem

\footnotetext{
${ }^{5}$ Micrograma
} 
de $1 \mathrm{mg} / \mathrm{kd} / \mathrm{dia}$, a partir de via intravenosa, por 5 dias. Tocilizumabe foi aplicada em dosagem de <75Kg:400mg iv >75 kg:600mg iv por 1 dia.

Lecronier et al. (2020) acompanharam 80 pacientes em condição severa de COVID-19, dos quais 38 passaram por tratamento padrão juntamente com Hidroxicloroquina (200mg duas vezes ao dia, a partir de via oral), 20 receberam tratamento padrão juntamente com Lopinavir/Ritonavir (400mg duas vezes ao dia por 5 dias) e 22 receberam apenas tratamento padrão. Para os respectivos grupos, a idade média é de 59 anos, 55 anos e 63 anos. Não foram demonstrados benefícios ou malefícios associados aos tratamentos envolvendo Hidroxicloroquina ou Lopinavir/Ritonavir.

Mahévas et al. (2020) avaliaram a eficácia da Hidoxicloroquina a partir de estudo observacional comparativo envolvendo pacientes hospitalizados que requeriam oxigênio, sendo dividido dois grupos: aqueles que receberam $600 \mathrm{mg} / \mathrm{dia}$ de Hidroxicloroquina $48 \mathrm{~h}$ após admissão ao hospital (84 pacientes, idade média de 59 anos) e grupo controle com tratamento padrão (89 pacientes, idade média de 62 anos). Azitromicina foi administrada a $18 \%$ dos pacientes no grupo em tratamento e $29 \%$ no grupo controle; e amoxilina para 52\% e ácido clavulânico para 28\%, respectivamente. Não houve redução na admissão de pacientes na Unidade de Tratamento Intensivo nem na taxa de fatalidade.

Objetivando entender se a Hidroxicloroquina possui alguma relação com a profilaxia do COVID-19, Vastarella et al. (2020) conduziram estudo retrospectivo observacional através de coleta de informações por telefone, de 66 pacientes que recebem a droga para tratamento de doenças dermatológicas e reumatológicas. Dos avaliados, 30 receberam tratamento contra doenças dermatológicas durante o período médio de 14.2 meses e 35 receberam tratamento contra doenças reumatológicas durante o período médio de 50.1 meses. 65 dos avaliados indicam não terem tido febre, dor de garganta, fadiga, tosse ou falta de ar nos dois meses prévios ao estudo, sugerindo a possibilidade de efeito profilático da Hidroxicloroquina. 
Também referente ao possível potencial profilático da Hidroxicloroquina, Boulware et al. (2020) avaliaram a droga quando aplicada a pessoas com alto risco de exposição a casos confirmados de COVID-19. 414 participantes fizeram parte do grupo que receberam Hidroxicloroquina em dose de $800 \mathrm{mg}$ uma vez, seguido de $600 \mathrm{mg}$ em 6 a 8 horas e outros $600 \mathrm{mg} /$ dia por 4 dias. 407 participantes foram designados para o grupo placebo. Não houve diferença significativa entre os dois grupos quanto à incidência de doença compatível com COVID-19.

Em estudo de Tang et al. (2020), 150 pacientes hospitalizados com idade média de 46 anos foram acompanhados em dois grupos: aqueles que receberam tratamento padrão e Hidroxicloroquina (75 pacientes) e aqueles que receberam apenas tratamento padrão (75 pacientes). 148 pacientes apresentavam doença de leve a moderada e apenas 2 tinham doença severa. Tratamento padrão inclui: administração de fluídos intravenosos, oxigênio suplementar, teste laboratorial periódico, teste de SARS-CoV-2, monitoramento hemodinâmico e tratamento intensivo. No grupo que recebeu a droga, dosagem inicial de 1200mg foi administrada por 3 dias, seguindo para $800 \mathrm{mg} /$ dia por 2-3 semanas, conforme nível de severidade. Não houve benefícios associados ao grupo que recebeu tratamento padrão e Hidroxicloroquina, em comparação ao segundo grupo.

Cavalcanti et al. (2020) investigaram três grupos de um total de 667 pacientes, sendo 504 casos confirmados com doença de leve a moderada: tratamento padrão ou grupo controle (229 pacientes), tratamento padrão e 400mg de Hidroxicloroquina duas vezes ao dia por 7 dias (221 pacientes), e tratamento padrão com a combinação de 400mg de Hidroxicloroquina duas vezes ao dia e 500mg de Azitromicina uma vez ao dia por 7 dias (217 pacientes). Tratamento de Hidroxicloroquina com ou sem Azitromicina não demonstrou prover melhora clínica entre os pacientes. Foi identificado, em comparação ao grupo controle, mais adversidades associadas ao tratamento com um ou ambos os medicamentos, como o mais frequente prolongamento do intervalo QT. 
Conforme Rosenberg et al. (2020), em estudo retrospectivo de coorte incluindo 1438 pacientes hospitalizados, Hidroxicloroquina associada ou não com a Azitromicina, em comparação com o não uso das duas drogas, não apresentou diferenças significativas com relação à diminuição de mortalidade.

Incluindo 90 pacientes hospitalizados com idade média de 60.1 anos, estudo de coorte dirigido por Mercuro et al. (2020) objetivou avaliar a relação do prolongamento do intervalo QT corrigido com o regime de 400mg de Hidroxicloroquina duas vezes no dia 1 , seguido por $400 \mathrm{mg} / \mathrm{dia}$ por outros 4 dias. Dois grupos (37 pacientes e 53 pacientes) receberam apenas Hidroxicloroquina e combinação de Hidroxicloroquina e Azitromicina, respectivamente. Não foi citado a dosagem para a Azitromicina. Conforme apresentado, o tratamento, envolvendo um ou ambos os medicamentos, mostra associação frequente com o prolongamento do intervalo QT corrigido.

Magagnoli et al. (2020) realizaram análise retrospectiva incluindo 368 veteranos (aqueles que atuaram na força militar, naval ou aérea) hospitalizados. Três grupos foram formados, sendo um grupo tratado com Hidroxicloroquina (97 pacientes, idade média de 70 anos); um grupo tratado com a combinação Hidroxicloroquina e Azitromicina (113 pacientes, idade média de 68 anos); e grupo controle (158 pacientes, idade média de 69 anos). Tanto o tratamento com Hidroxicloroquina apenas como em combinação com a Azitromicina não reduziu o risco de letalidade ou de uso de ventilação mecânica.

Bessière et al. (2020) acompanharam 40 pacientes com idade média de 68 anos, admitidos na Unidade de Tratamento Intensivo, sendo 18 tratados com a combinação de 200mg de Hidroxicloroquina duas vezes ao dia por 10 dias e 250mg de Azitromicina por dia por 5 dias e 22 tratados apenas com Hidroxicloroquina (200mg, duas vezes ao dia por 10 dias). Aumento do intervalo QT corrigido foi registrado em mais de $90 \%$ dos avaliados, sendo maior aumento associado ao tratamento com Hidroxicloroquina e Azitromicina. 
Van den Broek et al. (2020) também registraram prolongamento do intervalo QT corrigido em 95 pacientes com COVID-19 severo, idade média de 65 anos, que receberam tratamento baseado em $600 \mathrm{mg}$ de Cloroquina como dose de ataque, seguido de $300 \mathrm{mg}$ duas vezes ao dia por 5 dias. Hsia et al. (2020) registraram aumento do prolongamento do intervalo QT corrigido em 105 pacientes com idade média de 67 anos que receberam tratamento com Cloroquina (250mg ou $500 \mathrm{mg}$ ), Hidroxicloroquina $(400 \mathrm{mg}$ duas vezes no dia 1 e $400 \mathrm{mg} /$ dia por 4 dias) e Azitromicina (500mg no dia 1 e $250 \mathrm{mg} /$ dia por 4 dias) ou apenas Hidroxicloroquina. Prolongamento do intervalo QT corrigido também é demonstrado por Sinkeler et al. (2020), que acompanharam 397 pacientes, idade média de 67.8 anos, tratados a partir de $600 \mathrm{mg}$ de Cloroquina como dose de ataque, seguindo para $300 \mathrm{mg}$ duas vezes por dia durante 5 dias.

Achados de Dastan et al. (2020) indicam efeitos positivos em pacientes que receberam interferon beta-1a em combinação com Hidroxicloroquina e Lopinavir/Ritonavir. Fernández-Ruiz et al. (2020) acompanharam pacientes infectados pelo SARS-CoV-2 que passaram por transplante de órgãos sólidos. Monoterapia com Hidroxicloroquina foi aplicada a 5 pacientes, porém o estudo não suporta qualquer conclusão relativa aos medicamentos prescritos.

De acordo com descrição de Gao, Tian e Yang (2020), referente a uma coletiva de imprensa feita pelo Conselho de Estado da China, o uso da Cloroquina contra o Severe Acute Respiratory Syndrome Coronavirus 2 por mais de 100 pacientes levou a um resultado satisfatório quanto à diminuição dos sintomas da pneumonia.

Em ensaios in vitro (em células Vero E6) dirigidos por Wang et al. (2020), a fim de avaliar os efeitos de diferentes drogas antivirais em relação à citotoxicidade, ao rendimento e à taxa de infecção do SARS-CoV-2, a Cloroquina demonstrou conseguir bloquear o vírus em baixa concentração molar, com uma concentração efetiva de $50 \%\left(E C 50^{6}=1.13 \mu \mathrm{M}^{7}\right)$ e uma

\footnotetext{
${ }^{6}$ EC é a sigla em inglês para "Effective Concentration"; 50 refere-se à porcentagem da concentração.
} 
concentração citotóxica de 50\% (CC50 > $100 \mu \mathrm{M})$. Outras avaliações in vitro, porém demonstram que a Hidroxicloroquina tem maior efetividade na inibição do SARS-CoV-2 in vitro, em células Vero, do que a Cloroquina (2020).

Liu et al. (2020) avaliaram a Cloroquina e a Hidroxicloroquina in vitro contra o SARS-CoV-2, evidenciando a eficácia de ambas contra o vírus. Para comparação mais precisa, foram determinadas as curvas de dose/resposta em quatro diferentes tipos de multiplicidade de infecção (MOI, sigla em inglês), por quantificação dos números de cópias de RNA viral no sobrenadante das células Vero E6 após 48 horas de infecção. MOls: 0.01, $0.02,0.2$ e 0.8. Referida aos respectivos MOIs, a EC50 foi de: 2.71, 3.81, 7.14 e $7.36 \mu \mathrm{M}$ para Cloroquina e 4.71, 4.06, 17.31 e $12.96 \mu \mathrm{M}$ para Hidroxicloroquina. Em relação aos MOls 0.01 e 0.2 , valores de EC50 mostram-se significativamente diferentes.

\section{Conclusões}

A similaridade farmacocinética entre Cloroquina e Hidroxicloroquina leva a comparações frequentes destas duas drogas na literatura científica. É sugerido, então, que a abordagem de ambas possa levar a um estudo mais abrangente. Efeitos adversos relacionados à toxicidade por Cloroquina ou Hidroxicloroquina são evidenciados após meses ou até anos de uso, tempo expressivamente superior para o tratamento do COVID-19. No entanto, ainda há necessidade de se investigar se há efeitos adversos das duas drogas em pessoas infectadas pelo SARS-CoV-2. É imprescindível mencionar que o delineamento dos métodos científicos de cada estudo é importante para a interpretação dos resultados. Por exemplo, é necessário estar atento a condições específicas em que os componentes são estudados, como a dose efetiva ou concentração efetiva. Ambas podem ser diferentes em cada estudo. Outros fatores, como a característica da população avaliada (idade, comorbidades etc.), estágio da doença (leve,

\footnotetext{
${ }^{7}$ Micrômetro.

${ }^{8}$ CC é a sigla em inglês para "Cytotoxic Concentration"; 50 refere-se à porcentagem da concentração.
} 
moderada, severa), número de avaliados e tempo de administração da Cloroquina ou Hidroxicloroquina são necessários para interpretação. Tanto a Cloroquina como a Hidroxicloroquina demonstram potencial in vitro contra o SARSCoV-2. Estudos in vivo, no entanto, indicam resultados controversos de ambas as drogas contra o COVID-19. O grande número de lacunas que devem ser preenchidas por estudos ainda não nos leva a considerar a Cloroquina e Hidroxicloroquina como decisivas no tratamento ou profilaxia do COVID-19. 


\section{Referências}

ABDEL-HAMID H; ODDIS CV; LACOMIS D. Severe hydroxychloroquine myopathy. Muscle Nerve. v.38, p. 1206-1210. doi:10.1002/mus.21091.

AGA, Tomoni et al. Inhibition of autophagy by chloroquine makes chemotherapy in nasopharyngeal carcinoma more efficient. Auris Nasus Larynx v. 46, n. 3, p. 443-450, 2019. 10.1016/j.anl.2018.10.013.

ALAM, Masud et al. Inhibition of autophagy by chloroquine induces apoptosis in primary effusion lymphoma in vitro and in vivo through induction of endoplasmic reticulum stress. Apoptosis. v. 21, n. 10, p. 1191-201, 2016. 10.1007/s10495-016-1277-7.

AL-BARI, Abdul Alim. Chloroquine analogues in drug discovery: new directions of uses, mechanisms of actions and toxic manifestations from malaria to multifarious diseases. J Antimicrob Chemother. v. 70, n. 6, p. 1608-21, 2015. 10.1093/jac/dkv018.

AVNIEL-POLAK, Shani et al. Abrogation of Autophagy by Chloroquine Alone or in Combination with mTOR Inhibitors Induces Apoptosis in Neuroendocrine Tumor Cells. Neuroendocrinology. v. 103, n. 6, p. 724-37, 2016. 10.1159/000442589.

BESSIÈRE, Francis et al. Assessment of QT Intervals in a Case Series of Patients With Coronavirus Disease 2019 (COVID-19) Infection Treated With Hydroxychloroquine Alone or in Combination With Azithromycin in an Intensive Care Unit. JAMA Cardiol. 2020. 10.1001/jamacardio.2020.1787.

BISHOP, Bryan M. Potential and emerging treatment options for Ebola Virus Disease. Ann Pharmacother. v. 49, n. 2, p. 196-206, 2015. 10.1177/1060028014561227.

BISHOP, NE. Examination of potential inhibitors of hepatitis $A$ virus uncoating. Intervirology. v. 41, n. 6, 261-71, 1998. 10.1159/000024948.

BONDESON, Jan; SUNDLER Roger. antimalarial drugs inhibit phospholipase a2 activation and induction of interleukin $I \beta$ and tumor necrosis factor $\alpha$ in macrophages: implications for their mode of action in rheumatoid arthritis. Gen Pharmacol. v. 30, n. 3, p. 357-366, 1998. https://doi.org/10.1016/S0306-3623(97)00269-3.

BORBA, Mayla Gabriela Silva et al. Effect of high vs lowdoses of chloroquine diphosphate as adjunctive therapy for patients hospitalized with severe acute respiratory syndrome coronavirus 2 (sars-cov-2) infection: a randomized clinical trial. JAMA. v. 3, n. 4, e208857, 2020. 10.1001/jamanetworkopen.2020.8857.

BORGES, Marcos Carvalho; CASTRO, Luiza Antunes; FONSECA, Benedito Antonio Lopes. Chloroquine use improves dengue-related symptoms. Mem 
Inst Oswaldo Cruz. v. 108, n. 5 p. 596-599, 2013. 10.1590/00740276108052013010.

BOULWARE, David $\mathrm{R}$ et al. A Randomized Trial of Hydroxychloroquine as Postexposure Prophylaxis for Covid-19. N Engl J Med. 2020. 10.1056/NEJMoa2016638.

BOZDECH Z; GINSBURG H. Antioxidant defense in Plasmodium falciparum - data mining of the transcriptome. Malar J. 2004; 3:23. 10.1186/1475-28753-23.

BRASIL. Ministério da saúde. Fundação Oswaldo Cruz (FIOCRUZ). Orientações sobre o uso da Cloroquina para tratamento de pacientes infectados com SARS-CoV-2, agente etiológico da Covid-19. Disponível em:

https://portal.fiocruz.br/sites/portal.fiocruz.br/files/documentos/orientacoes_so bre_a_cloroquina_nota_tecnica_.pdf. Acesso em: 29 julho 2020.

CAVALCANTI, Alexandre B et al. Hydroxychloroquine with or without Azithromycin in Mild-to-Moderate Covid-19. N Engl J Med. 2020. 10.1056/NEJMoa2019014.

CAVE, Donatella Delle et al. S-Adenosylmethionine-mediated Apoptosis Is Potentiated by Autophagy Inhibition Induced by Chloroquine in Human Breast Cancer Cells. J Cell Physiol. v. 233, n. 2, p. 1370-1383, 2018. 10.1002/jcp.26015.

CHAFIN, Cristen B et al. Cellular and urinary microRNA alterations in NZB/W mice with hydroxychloroquine or prednisone treatment. Int Immunopharmacol. v. 17, n. 3, 2013. 10.1016/j.intimp.2013.09.013.

CHATRE, Clotilde et al. Cardiac Complications Attributed to Chloroquine and Hydroxychloroquine: A Systematic Review of the Literature. Drug Saf. v. 41, n. 10 , p. $919-931,2018.10 .1007 / \mathrm{s} 40264-018-0689-4$.

CHEN, S; WU, K; KNOX, R. Structure-function studies of DT-diaphorase (NQO1) and NRH: quinone oxidoreductase (NQO2). Free Radical Biol Med. v. 29 , n. 3-4, p. 276-284, 2000. 10.1016/s0891-5849(00)00308-7.

$\mathrm{CHOU}, \mathrm{AC}$; FITCH, CD. Heme polymerase: modulation by chloroquine treatment of a rodent malaria. Life Sci. v. 51, n. 26, p. 2073-8, 1992. 10.1016/0024-3205(92)90158-I.

COLSON, Philippe; ROLAIN, Jean-Marc; RAOULT, Didier. Chloroquine for the 2019 novel coronavirus SARS-CoV-2. Int J Antimicrob Agents. v. 55, n. 3, 2020. https://doi.org/10.1016/j.ijantimicag.2020.105923.

COMBRINCK, Jill $M$ et al. Insights into the role of heme in the mechanism of action of antimalarials. ACS Chem Biol. v. 8, n. 1, p. 133-137, 2013. 10.1021/cb300454t. 
CORONADO, Lorena M; NADOVICH, Christopher T; SPADAFORA, Carmenza. Malarial hemozoin: from target to tool. Biochim Biophys Acta. v. 1840, n. 6, p. 2032-41, 2014. 10.1016/j.bbagen.2014.02.009.

CORTEGIANI, Andrea et al. A systematic review on the efficacy and safety of chloroquine for the treatment of COVID-19. J Clit Care. v. 57, p. 279-283, 2020. 10.1016/j.jcrc.2020.03.005.

DASTAN, Farzaneh et al. Subcutaneous administration of interferon beta-1a for COVID-19: A noncontrolled prospective trial. Int Immunopharmacol. v. 85, 2020. 10.1016/j.intimp.2020.106688.

DE WILDE, Adriaan $\mathrm{H}$ et al. Screening of an FDA-approved compound library identifies four small-molecule inhibitors of Middle East respiratory syndrome coronavirus replication in cell culture. Antimicrob Agents Chemother. v. 58, n. 8, p. 4875-84, 2014. 10.1128/AAC.03011-14.

DEVAUX, Christian A et al. New insights on the antiviral effects of chloroquine against coronavirus: what do expect for COVID-19. Int $\mathbf{J}$ Antimicrob Agents. v. 55, n. 5, 2020 doi: 10.1016/j.jjantimicag.2020.105938.

DING, Hui Jen et al. Hydroxychloroquine-related retinal toxicity. Rheumatology (Oxford). v. 55, n. 6, p. 957-967, 2016. 10.1093/rheumatology/kev357.

DINKOVA-KOSTOVA, AT; TALALAY, P. Persuasive evidence that quinone reductase type 1 (DT diaphorase) protects cells against the toxicity of electrophiles and reactive forms of oxygen. Free Radical Biol Med. v. 29, n. 3-4, p. 231-240, 2000. 10.1016/s0891-5849(00)00300-2.

DOMINGUEZ-GUTIERREZ, Paul $\mathrm{R}$ et al. Reduced levels of CCL2 and CXCL10 in systemic lupus erythematosus patients under treatment with prednisone, mycophenolate mofetil, or hydroxychloroquine, except in a high STAT1 subset. Arthritis Res. Ther. v. 16, n. 23, 2014. https://doi.org/10.1186/ar4451.

DONG, Liying; HU, Shasha; GAO, Jianjun. Discovering drugs to treat coronavirus disease 2019 (COVID-19). Drug Discov Ther. v. 14, n. 1, p. 5860, 2020. 10.5582/ddt.2020.01012.

DOWALL, Stuart $\mathrm{D}$ et al. Chloroquine inhibited Ebola virus replication in vitro but failed to protect against infection and disease in the in vivo guinea pig model. J Gen Virol. v. 96, n12, p. 3484-3492, 2015. 10.1099/jgv.0.000309.

DUCHARME, J; FARINOTTI, R. Clinical pharmacokinetics and metabolism of chloroquine. Focus on recent advancements. Clin Pharmacokinet. v. 31, n. 4, p. 257-74, 1996. 10.2165/00003088-199631040-00003.

EADIE MJ, Ferrier TM. Chloroquine myopathy. J Neurol Neurosurg Psychiatr. v. 29, p. 331-37, 1966. 
EGAN, Timothy J. Haemozoin formation. Mol Biochem Parasitol. v. 157, n. 2, p. 127-36, 2008. 10.1016/j.molbiopara.2007.11.005.

EMBI, Mohammed Noor; GANESAN, Nagessway; SIDEK, Hasidah Mohd. Is GSK3 $\beta$ a molecular target of chloroquine treatment against COVID-19. Drug Discov Ther. v. 14, n. 2, p. 107-108. 10.5582/ddt.2020.03010.

FANOURIAKIS, Antonis et al. 2019 update of EULAR recommendations for the management of systemic lupus erythematosus. Ann Rheum Dis. v. 78, p. 736-745, 2019. http://dx.doi.org/10.1136/annrheumdis-2019-215089.

FANTINI, Jacques et al. Structural and molecular modelling studies reveal a new mechanism of action of chloroquine and hydroxychloroquine against SARS-CoV-2 infection. Int J Antimicrob Agents. v. 55, n. 5, 2020. 10.1016/j.ijantimicag.2020.105960.

FERNÁNDEZ-RUIZ, Mario et al. COVID-19 in solid organ transplant recipients: A single-center case series from Spain. Am J Transplant. v. 20, n. 7, p. 1849-1858. 2020 10.1111/ajt.15929.

FOX RI. Mechanism of action of hydroxychloroquine as an antirheumatic drug. Semin Arthritis Rheum; v. 23, p. 82-91. 10.1016/s00490172(10)80012-5.

FOX, Robert I; KANG, HO-II. Mechanism of Action of Antimalarial Drugs: Inhibition of Antigen Processing and Presentation. Lupus. v. 2, n; 1, p. 9-12, 1993. https://doi.org/10.1177/0961203393002001031.

FUKUDA, Tomohiko et al. The anti-malarial chloroquine suppresses proliferation and overcomes cisplatin resistance of endometrial cancer cells via autophagy inhibition. Gynecol Oncol. v. 137, n. 3, p. 538-545, 2015. https://doi.org/10.1016/j.ygyno.2015.03.053.

FURST, DE et al. Dose-loading with hydroxychloroquine improves the rate of response in early, active rheumatoid arthritis: a randomized, double-blind sixweek trial with eighteen-week extension. Arthritis Rheum. v. 42, n. 2, p. 357-65, 1999. 10.1002/1529-0131(199902)42:2<357::AID-ANR19>3.0.CO;2$\mathrm{J}$

GAO, Jianjun; TIAN, Zhenxue; YANG, Xu. Breakthrough: Chloroquine phosphate has shown apparent efficacy in treatment of COVID-19 associated pneumonia in clinical studies. Biosci Trends. v. 14, n. 1, p. 72-73, 2020. 10.5582/bst.2020.01047.

GAUTRET, Philippe et al. Hydroxychloroquine and azithromycin as a treatment of COVID19: results of an open-label non-randomized clinical trial. Int J Antimicrob Agents. v. 56, n. 1, 2020. 10.1016/j.ijantimicag.2020.105949.

GELERIS, Joshua et al. Observational Study of Hydroxychloroquine in Hospitalized Patients with Covid-19. N Engl J Med. v. 382, p. 2411-2418, 2020. 10.1056/NEJMoa2012410. 
GOICOECHEA, Marian et al. COVID-19: clinical course and outcomes of 36 hemodialysis patients in Spain. Kidney Int. v. 98, n. 1, p. 27-34, 2020. 10.1016/j.kint.2020.04.031.

GOLDMAN, FD et al. Hydroxychloroquine inhibits calcium signals in t cells: a new mechanism to explain its immunomodulatory properties. Blood. v. 95, n. 11 , p. 3460-66, 2000.

GUASTALEGNAME, Maurizio; VALLONE, Alfredo. Could chloroquine/hydroxychloroquine be harmful in Coronavirus Disease 2019 (COVID-19) treatment? Clin Infect Dis. v. 71, n. 15, p. 888-889, 2020. $10.1093 /$ cid/ciaa321.

HALLIWELL, William H. Cationic amphiphilic drug-induced phospholipidosis. Toxicol Pathol. v. 25, n. 1, p. 53-60, 1997. 10.1177/019262339702500111.

HSIA, Brian C et al. QT prolongation in a diverse, urban population of COVID-19 patients treated with hydroxychloroquine, chloroquine, or azithromycin. J Interv Card Electrophysiol. p. 1-9, 2020 10.1007/s10840020-00822-x.

HU, Tony Y; FRIEMAN, Matthew; WOLFAMN, Joy. Insights from nanomedicine into chloroquine efficacy against COVID-19. Nat Nanotechnol. v. 15, p. 247-249, 2020. 10.1038/s41565-020-0674-9.

HUANG, Mingxing et al. Treating COVID-19 with Chloroquine. J Mol Cell Biol. v. 12, n. 4, p. 322-325, 2020. 10.1093/jmcb/mjaa014.

JARAUTA, Vidal et al. Inhibition of autophagy with chloroquine potentiates carfilzomib-induced apoptosis in myeloma cells in vitro and in vivo. Cancer Lett.. v. 382, n. 1, p. 1-10, 2016. 10.1016/j.canlet.2016.08.019.

KEYAERTS, Els et al. In vitro inhibition of severe acute respiratory syndrome coronavirus by chloroquine. v. 323, n. 1, p. 264-268, 2004. 10.1016/j.bbrc.2004.08.085.

KRONENBERGER, P; Vrijsen, R. Boeyé, A. Chloroquine induces empty capsid formation during poliovirus eclipse. J Virol. v. 65, n. 12, p. 7008-11, 1991.

KWIEK, Jesse J; HAYSTEAD, Timothy AJ; RUDOLPH, Johannes. Kinetic Mechanism of Quinone Oxidoreductase 2 and Its Inhibition by the Antimalarial Quinolines. Biochemistry. v. 43, 15, p. 4538-47, 2004. 10.1021/bi035923w.

LAl, Ching-Cheng $\mathrm{C}$ et al. Asymptomatic carrier state, acute respiratory disease, and pneumonia due to severe acute respiratory syndrome coronavirus 2 (SARSCoV-2): Facts and myths. J Microbiol Immunol Infect. v. 53, n. 3, p. 404-412, 2020. 10.1016/j.jmii.2020.02.012.

LECRONIER, Marie et al. Comparison of hydroxychloroquine, lopinavir/ritonavir, and standard of care in critically ill patients with SARS- 
CoV-2 pneumonia: an opportunistic retrospective analysis. Crit Care. v. 24, n. 1 , p. $418,2020.10 .1186 / \mathrm{s} 13054-020-03117-9$.

LESIAK, A et al. Effect of chloroquine phosphate treatment on serum MMP-9 and TIMP-1 levels in patients with systemic lupus erythematosus. Lupus. v. 19, n. 6, p. 683-688, 2010. 10.1177/0961203309356455.

LESTER, RS et al. Immunologic concepts of light reactions in lupus erythematosus and polymorphous light eruptions. i. the mechanism of action of hydroxychloroquine. Arch Dermatol. v. 96, n. 1, p. 1-10, 1967.

$\mathrm{LI}$, Wenhui et al. Angiotensin-converting enzyme 2 is a functional receptor for the SARS coronavirus. Nature. v. 426, p. 450-54, 2003. https://doi.org/10.1038/nature02145.

LIU, Jia et al. Hydroxychloroquine, a less toxic derivative of chloroquine, is effective in inhibiting SARS-CoV-2 infection in vitro. Cell Discov. v. 6, n. 16, 2020. https://doi.org/10.1038/s41421-020-0156-0.

LOFFLER, BM et al. Effects of Antimalarial Drugs on Phospholipase A and Lysophospholipase Activities in Plasma Membrane, Mitochondrial, Microsomal and Cytosolic Subcellular Fractions of Rat Liver. Biochim Biophys Acta. v. 835, n. 3, p. 448-55, 1985. 10.1016/0005-2760(85) 901146.

LONG, DJ 2 ${ }^{\text {nd; }}$ JAISWAL, AK. NRH: quinone oxidoreductase 2 (NQO2). Chem Biol Interact. v. 129, n. 1-2, p. 99-112, 2000. 10.1016/s00092797(00)00200-3.

MAES, Hannelore et al. Chloroquine anticancer activity is mediated by autophagy-independent effects on the tumor vasculature. Mol Cell Oncol. v. 3, n. 1, 2016. 10.4161/23723548.2014.970097.

MAGAGNOLI, Joseph et al. Outcomes of hydroxychloroquine usage in United States veterans hospitalized with Covid-19. Med (NY). 2020. 10.1016/j.medj.2020.06.001.

MAHALINGAM, Suresh et al. Hendra virus: an emerging paramyxovirus in Australia. Lancet Infec Dis. v. 12, n. 10, p. 799-807, 2012. 10.1016/S14733099(12)70158-5.

MAHÉVAS, Matthieu et al. Clinical efficacy of hydroxychloroquine in patients with covid-19 pneumonia who require oxygen: observational comparative study using routine care data. BMJ. v. 369, m1844, 2020. https://doi.org/10.1136/bmj.m1844.

MAHON, GJ et al. Chloroquine causes lysosomal dysfunction in neural retina and RPE: implications for retinopathy. Curr Eye Res v. 28, n. 4, p. 277-84, 2004. 10.1076/ceyr.28.4.277.27835. 
MARMOR, Michael $\mathrm{F}$ et al. Recommendations on screening for Chloroquine and Hydroxychloroquine retinopathy (2016 Revision). Ophthalmology. v. 123 , n. 6, p. 1386-94, 2016. 10.1016/j.ophtha.2016.01.058.

MARMOR, Michal F; HU, Julia. Effect of disease stage on progression of hydroxychloroquine retinopathy. JAMA ophthalmol. v. 132, n. 9, p. 1105-12, 2014. 10.1001/jamaophthalmol.2014.1099..

MERCURO, Nicholas $\mathrm{J}$ et al. Risk of QT Interval Prolongation Associated With Use of Hydroxychloroquine With or Without Concomitant Azithromycin Among Hospitalized Patients Testing Positive for Coronavirus Disease 2019 (COVID-19). JAMA Cardiol. 2020. 10.1001/jamacardio.2020.1834.

MESHNICK, SR. Chloroquine as intercalator: a hypothesis revived. Parasitol. v. 6, n. 3, p. 77-79, 1990. https://doi.org/10.1016/01694758(90)90215-P.

MIZUI, Tomokazu et al. Inhibition of hepatitis C virus replication by chloroquine targeting virus-associated autophagy. J Gastroenterol. v, 45, n. 2, p. 195-203, 2010. 10.1007/s00535-009-0132-9.

MOLINA, JM et al. No evidence of rapid antiviral clearance or clinical benefit with the combination of hydroxychloroquine and azithromycin in patients with severe COVID-19 infection. Med Mal Infect. v. 50, n. 4, p. 384, 2020. 10.1016/j.medmal.2020.03.006.

NEVILLE, Hans E et al. Chloroquine-induced cytosomes with curvilinear profiles in muscle. Muscle Nerve. v. 2, 376-381, 1979.

PATEL, Haridarshan et al. Prevalence of Cardiac Risk Factors in Patients Prescribed Azithromycin Before and After the 2012 FDA Warning on the Risk of Potentially Fatal Heart Rhythms. Pharmacotherapy. v. 40, n. 2, p. 107115, 2020. 10.1002/phar.2355.

PATON, Nicholas I et al. Chloroquine for influenza prevention: a randomized, double-blind, placebo controlled trial. Lancet Infect Dis. v. 11, n. 9, p. 67783, 2011. 10.1016/S1473-3099(11)70065-2.

PETRI, Michelle. Hydroxychloroquine: past, present, future. Lupus. v. 7, n. 2, p. 65-67, 1998. https://doi.org/10.1191/096120398678919886.

PICOT, Stéphane et al. Chloroquine inhibits tumour necrosis factor production by human macrophages in vitro. J Infect Dis. v. 164, n. 4, p. 830. 1991. https://doi.org/10.1093/infdis/164.4.830.

PLANTONE, Domenico; KOUDRIAVTSEVA, Tatiana. Current and Future Use of Chloroquine and Hydroxychloroquine in Infectious, Immune, Neoplastic, and Neurological Diseases: A Mini-Review. Clin Drug Investig. v. 38, n. 8, p. 653-671, 2018. 10.1007/s40261-018-0656-y.

RODRIGUEZ-CARUNCHO, C; MARSOL, I Bielsa. Antimalarials in Dermatology: Mechanism of Action, Indications, and Side Effects. Actas 
Dermosifiliogr. v. 105, n. $\quad 3, \quad$ p. $243-252, \quad 2014$. https://doi.org/10.1016/j.adengl.2012.10.021.

ROQUES, Pierre et al. Paradoxial effect of Chloroquine treatment in enhancing Chikungunya Virus infection. Viruses. v. 10, n. 5, p. 268, 2018. 10.3390/v10050268.

ROSENBERG, Eli S et al. Association of Treatment With Hydroxychloroquine or Azithromycin With In-Hospital Mortality in Patients With COVID-19 in NewYork State. JAMA. v. 323, n. 24, p. 2493-2502, 2020. 10.1001/jama.2020.8630.

RUBINSZTEIN, David C; CODOGNO, Patrice; LEVINE, Beth. Autophagy modulation as a potential therapeutic target for diverse diseases. Nat Rev Drug Discov. v. 11, n. 9, p. 709-730, 2012. 10.1038/nrd3802.

SALEH, Moussa et al. Effect of chloroquine, hydroxychloroquine, and azithromycin on the corrected qt interval in patients with SARS-CoV-2 infection. Circ Arrhythm Electrophysiol. v. 13. N. 6, e008662, 2020. 10.1161/CIRCEP.120.008662.

SAPP, John $\mathrm{L}$ et al. Guidance on Minimizing Risk of Drug-Induced Ventricular Arrhythmia During Treatment of COVID-19: A Statement From the Canadian Heart Rhythm Society. Can J Cardiol. v. 36, n. 6, p. 948-951, 2020. 10.1016/j.cjca.2020.04.003.

SAVARINO, Andrea et al. Effects of chloroquine on viral infections: an old drug against today's diseases? Lancet Infec Dis. v. 3, n. 11, p. 722-7, 2003. 10.1016/s1473-3099(03)00806-5.

SAVARINO, Andrea et al. New insights into the antiviral effects of chloroquine. Lancet Infect Dis. v. 6, n. 2, p. 67-69, 2006. 10.1016/S14733099(06)70361-9.

SAVARINO, Andrea et al. The anti-HIV-1 activity of Chloroquine. J Clin Virol. v. 20, n. 3, p. 131-5, 2001. 10.1016/s1386-6532(00)00139-6.

SCHONEWOLF, Caitlin A et al. Autophagy Inhibition by Chloroquine Sensitizes HT-29 Colorectal Cancer Cells to Concurrent Chemoradiation. World J Gastrointest Oncol. v. 6, n. 3, p. 74-82, 2014. 10.4251/wjgo.v6.i3.74.

SCHREZENMEIER, Eva; DORNER, Thomas. Mechanisms of action of hydroxychloroquine and chloroquine: implications for rheumatology. Nat Rev Rheumatol. v. 16, n. p. 155-166, 2020. 10.1038/s41584-020-0372-x.

SIDHU, Amar Bir Singh; VERDIER-PINARD, Dominkik; FIDOCK, David A. Chloroquine resistance in plasmodium falciparum malaria parasites conferred by pfcrt mutations. Science. v. 298, n. 5591, p. 210-213, 2002. 10.1126/science. 1074045 . 
SILVA, Juliana Cruz da et al. Hydroxychloroquine decreases Th17-related cytokines in systemic lupus erythematosus and rheumatoid arthritis patients. Clinics (São Paulo). v. 68, n. 6,p. 766-771, 2013. 10.6061/clinics/2013(06)07.

SINKELER, FS et al. The risk of QTC-interval prolongation in COVID-19 patients treated with chloroquine. Neth Heart J. v. 28, p. 418-423, 2020. 10.1007/s12471-020-01462-6.

SISTERNES $\mathrm{L}$ et al. Localization of Damage in Progressive Hydroxychloroquine Retinopathy On and Off the Drug: Inner Versus Outer Retina, Parafovea Versus Peripheral Fovea. Invest Ophthalmol Vis Sci. v. 56, n. 5. p. 3415-3426, 2015. 10.1167/iovs.14-16345.

SMITH, B; O'Grady F. Experimental chloroquine myopathy. J Nerol Neurosurg Psychiat. v. 29, n. 3, p. 255-8, 1966. 10.1136/jnnp.29.3.255.

SMOLEN, Josef $S$ et al. EULAR recommendations for the management of rheumatoid arthritis with synthetic and biological disease-modifying antirheumatic drugs: 2013 update. Ann Rhem Dis. v. 73, p. 492-509, 2014. http://dx.doi.org/10.1136/annrheumdis-2013-204573.

SOLOMON, V Raja; LEE, Hoyun. Chloroquine and its analogs: A new promise of an old drug for effective and safe cancer therapies. Eur $\mathbf{J}$ Pharmacol. v. 625, n. 1-3, p. 220-233, 2009. https://doi.org/10.1016/j.ejphar.2009.06.063.

STEPHEN, M Weber; STUART, M Levitz. Chloroquine Interferes with Lipopolysaccharide - Induced TNF- $\alpha$ Gene Expression by a Nonlysosomotropic Mechanism. J Immunol. v. 165, n. 3, p. 1534-40, 2000. https://doi.org/10.4049/jimmunol.165.3.1534.

SUGIOKA, $Y$ et al. A ferriprotoporphyrin IX-chloroquine complex promotes membrane phospholipid peroxidation. A possible mechanism for antimalarial action. FEBS Lett. v. 223, n. 2, p. 251-4, 1987. 10.1016/00145793(87)80299-5.

TANG, Wei et al. Hydroxychloroquine in patients with mainly mild to moderate coronavirus disease 2019: open label, randomised controlled trial. BMJ. v. 369, m1849, 2020. 10.1136/bmj.m1849.

TEKTONIDOU, Maria G et al. EULAR recommendations for the management of antiphospholipid syndrome in adults. Ann Rheum Dis. v. 78, p. 12961304, 2019. http://dx.doi.org/10.1136/annrheumdis-2019-215213.

TEWARI, Shivendra G et al. Using a genome-scale metabolic network model to elucidate the mechanism of chloroquine action in Plasmodium falciparum. Int J Parasitol Drugs Resist. v. 7, n. 2, p. 138-146, 2017. 10.1016/j.jpddr.2017.03.004.

TONNESMANN, Ernst; KANDOLF, Reinhard; LEWALTER, Thorsten. Chloroquine cardiomyopathy - a review of the literature. Immunopharmacol 
Immunotoxicol. v. 35, n. 3, p. 434-42, 2013. 10.3109/08923973.2013.780078.

TOURET, Franck; LAMBALLERIE, Xavier de. Of chloroquine and COVID-19. Antiviral Res. v. 177, 2020;177. 10.1016/j.antiviral.2020.104762.

TRICOU, Vianney et al. A randomized controlled trial of Chloroquine for the treatment of Dengue in Vietnamese adults. PLoS Negl Trop Dis. v. 4, n. 8, e785, 2010. 10.1371/journal.pntd.0000785.

TSIANG, H; SUPERTI, F. Ammonium Chloride and Chloroquine Inhibit Rabies Virus Infection in Neuroblastoma Cells. Arch Virol. v. 81, n. 3-4, 37782, 1984. 10.1007/bf01310010.

VAN BEEK, Marta J; PIETTE, Warren W. Antimalarials. Dermatol Clinics. v. 19, n. 1, p. 147-160. https://doi.org/10.1016/S0733-8635(05)70236-9.

VAN DE BROEK, MPH et al. Chloroquine-induced QTc prolongation in COVID-19 patients. Neth Heart J. p. 1-4, 2020. https://doi.org/10.1007/s12471-020-01429-7.

VASTARELLA, Maria et al. Can hydroxychloroquine be useful in the prevention of COVID-19? An Italian survey in dermatologic and rheumatologic patients already under treatment. J Am Acad Dermatol. v. 83, n. 1, e77-e79, 2020. 10.1016/j.jaad.2020.04.136.

VINCENT, Martin $\mathrm{J}$ et al. Chloroquine is a potent inhibitor of SARS coronavirus infection and spread. Virol J. v. 2, n. 69, 2005. https://doi.org/10.1186/1743-422X-2-69.

VIVINO, Frederick B et al. New treatment guidelines for Sjögren's Disease. Rheum Dis Clin North Am. v. 42, n. 3, p. 531-551, 2016. https://doi.org/10.1016/j.rdc.2016.03.010.

WALLACE, Daniel $\mathrm{J}$ et al. New insights into mechanisms of therapeutic effects of antimalarial agents in SLE. Nat Rev Rheumatol. v. 8, 9. p. 522533, 2012. 10.1038/nrrheum.2012.106.

WALLACE, Daniel J. Antimalarials - the 'real' advance in lupus. Lupus. v. 10, n. 6, p. 385-7. 2001. 10.1191/096120301678646092.

WALLS, Alexandra C et al. Structure, Function, and Antigenicity of the SARS-CoV-2 Spike Glycoprotein. Cell. v. 181, n. 2, p. 281-292, 2020. https://doi.org/10.1016/j.cell.2020.02.058.

WANG, $\mathrm{F}$ et al. Chloroquine enhances the radiosensitivity of bladder cancer cells by inhibiting autophagy and activating apoptosis. Cell Physiol Biochem. v. 45, n. 1, p. 54-66, 2018. https://doi.org/10.1159/000486222.

WANG, Hongcheng et al. Gambogic acid induces autophagy and combines synergistically with chloroquine to suppress pancreatic cancer by increasing 
the accumulation of reactive oxygen species. Cancer Cell Int. v. 19, n. 7, 2019. 10.1186/s12935-018-0705-X.

WANG, Manli et al. Remdesivir and Chloroquine effectively inhibit the recently emerged novel coronavirus (2019-nCoV) in vitro. Cell Res. v. 30, p. 269-271. 2020. https://doi.org/10.1038/s41422-020-0282-0.

WU, Fan et al. A new coronavirus associated with human respiratory disease in China. Nature. v. 579, p. 265-269, 2020. https://doi.org/10.1038/s41586020-2008-3.

WU, Liqi et al.. Chloroquine enhances replication of Influenza A virus A/WSN/33 (H1N1) in dose, time, and Mol dependent manners in human lung epithelial cells A549. J Med Virol. v. 87, 7, p. 1096-103, 2015. 10.1002/jmv.24135.

YAO, Xueting et al. In Vitro Antiviral Activity and Projection of Optimized Dosing Design of Hydroxychloroquine for the Treatment of Severe Acute Respiratory Syndrome Coronavirus 2 (SARS-CoV-2). Clin Infect Dis. v. 71, n. 15, p. 732-739. 2020. https://doi.org/10.1093/cid/ciaa237.

YAYON, A et al. Stage-Dependent Effects of Chloroquine on Plasmodium falciparum In Vitro. J Protozool. v. 30, n. 4, p. 642-7, 1983. 10.1111/j.15507408.1983.tb05336.x

YAZDANY, Jinoos; KIM, Alfred HJ. Use of Hydroxychloroquine and Chloroquine During the COVID-19 Pandemic: What Every Clinician Should Know. Ann Inter Med. v. 172, n. 11, p. 754-755, 2020. 10.7326/M20-1334.

YOGASUNDARAM, Haran et al. Hydroxychloroquine-induced cardiomyopathy: case report, pathophysiology, diagnosis, and treatment. Can J Cardiol. v. 30, n. 12, p. 1706-1715, 2014. 10.1016/j.cjca.2014.08.016.

ZHANG, Cantong et al. Controversial treatments: an updated understanding of the Coronavirus Disease 2019. J Med Virol. 2020. 10.1002/jmv.25788.

ZHOU, Dan; Dai, Sheng-Ming. Tong, Qiang. COVID-19: a recommendation to examine the effect of hydroxychloroquine in preventing infection and progression. J Antimicrob Chemother. v. 75, n. 7, p. 1667-1670, 2020. 10.1093/jac/dkaa114.

ZHU, Bing et al. Inhibition of autophagy with chloroquine enhanced sinoporphyrin sodium mediated photodynamic therapy-induced apoptosis in human colorectal cancer cells. Int J Biol Sci. v. 15, n. 1, p. 12-33, 2019. 10.7150/ijbs.27156. 